\title{
A child With Fanconi anaemia
}

Puvana $A^{l}$, Sathiadas $M G^{l}$

${ }^{1}$ Teaching Hospital Jaffna.

Corresponded Author: Sathiadas, M.G.

\section{Abstract}

Fanconi anemia (FA) is an inherited bone marrow failure syndrome characterized by pancytopenia, physical abnormalities and predisposition to malignancy. It is due to DNA repair defect results in genomic instability. Diagnosis is done by chromosomal fragility test which is high sensitive and low specific test. In this case report, a nine year old girl was accidentally identified with bicytopenia during febrile illness with reactive bone marrow initially. It was followed by pancytopenia with hypocellular marrow. She was diagnosed as FA with classic physical findings of café au lait spots, microcephaly, torticollis, hypocellular bone marrow, positive mitomycin-C stress cytogenetic test and high $\mathrm{HbF}$.

(Key words: Pancytopenia, Fanconi anaemia, Chromosomal fragility)

\section{Introduction}

FA is primarily inherited in an autosomal recessive manner (uncommon forms are X-linked recessive and autosomal dominant). It is caused by one of atleast 17 different genes (FANCA to FANCQ). (1) At presentation, patients with FA may have: Typical physical anomalies and abnormal hematological findings (majority of the patients); Normal physical features but abnormal hematological findings (about one third of patients); or Physical anomalies and normal hematological findings (unknown percentage). (2) Common physical findings are thumb and radial malformations, hyper pigmented skin lesions (café-au-lait spots) and malformations belonging to the VACTERL-H. The screening laboratory test for this defect involves assessment of chromosomal breakage upon exposure of cells to diepoxybutane (DEB) or mitomycin-C (MMC) on $\mathrm{T}$ lymphocytes in peripheral blood. FA gene sequencing is recommended for all patients with a positive result from chromosomal breakage testing (3). Allogeneic hematopoietic cell transplantation is the only established curative therapy. Androgen therapy is not curative, but it may be appropriate for patients awaiting HCT or those who cannot undergo HCT.

\section{Case report}

Nine year old fourth consanguineous product with healthy siblings was transferred from local hospital for further evaluation of pancytopenia. Her birth birth weight was $2.065 \mathrm{~kg}$ (LBW) and she had microcephaly $(\mathrm{OFC}-30 \mathrm{~cm})$. She was initially investigated for persistent bicytopenia which was identified accidentally when she was admitted with febrile illness at the age of four years. On examination she was found to have microcephaly, multiple café-au-lait spots and right side torticollis without any skeletal deformities. Initial investig -ations (at 4 years) were WBC-3200/mm3, absolute neutrophil count- 307/mm3, PLT-49000/ mm3, Hb-11.1gdl-1, MCV-92fl, blood picture bicytopenia related to recent infection, HPLChigh $\mathrm{HbF}$ with normal $\mathrm{RBC}$ indices noted (HbA$71.5 \%, \mathrm{HbA} 2-1.6 \%, \mathrm{HbF}-19.5 \%$ ). The $2 \mathrm{D}$ Echo, USS of Kidneys were normal. The initial bone marrow biopsy suggested vitamin B12 deficiency and she received B12 injections. Despite this the pancytopenia persisted. The second bone marrow showed hypo cellular marrow for the age without any evidence of infiltration. She was lost for follow up for 2 years and returned with a vaginal itch which was treated as candidiasis. The chromosome fragility test showed MMC stress cytogenetic test was positive. (figure 1) We concluded this case as fanconi anemia as she has pancytopenia some suggestive physical findings with positive chromosomal fragility test. We couldn't confirm with FA gene sequencing as they couldn't afford it. She was started with danazole after fourth bone marrow biopsy as they couldn't afford hematopoietic stem cell transplantation (HCT). We explained again regarding disease and compliance with treatment as she had recurrent defaulted follow up. 


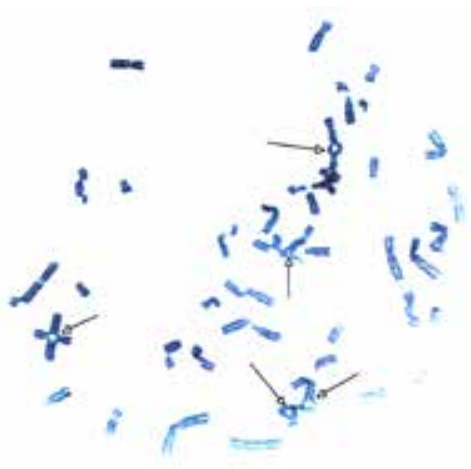

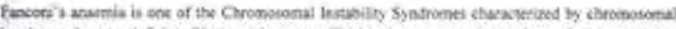

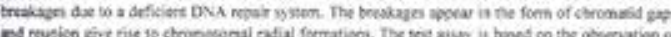

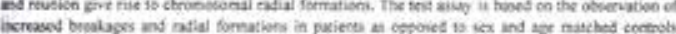

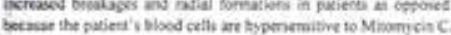

Figure 1: Chromosome fragility test

\section{Discussion}

Majority of the patients are having classic physical findings. Even though presence of these findings provide an important clue to the diagnosis, their absence doesn't eliminate the possibility of FA. Thrombocytopenia and red blood cells (RBC) macrocytosis often appears initially, with subsequent onset of granulocytopenia and then anemia as in our case report. Diagnostic delays are common in FA. Testing for FA is absolutely and urgently indicated in any child with two or more severe cytopenias and reduced bone marrow cellularity in the absence of known cause.(3) Diagnostic testing for FA is done by assessment of chromosomal breakage upon exposure of peripheral blood lymphocytes or skin fibroblasts to DEB or MMC. Chromosomal fragility test can be false negative in $10-15 \%$ of patients because of somatic mosaicism. (4) It can be false positive in non-FA chromosomal instability syndromes such as Nijmegan breakage syndrome, bloom syndrome, ataxia telangiectasia, roberts syndrome and seckel syndrome. (4) This is due to overlapping values of currently used chromosomal fragility indexes (CFI-percentage of cells with breaks or average number of breaks per cell) between non FA and FA mosaics. By using clear cutoff values of CFI, we can reduce the false results. Chromosome sequencing was not performed due to the cost of the test and finally concluded as FA with classic physical findings, high $\mathrm{HbF}$, hypocellular marrow and positive chromosomal fragility test. Genetic counseling was done to family.

\section{References}

1. D'Andrea AD, Grompe M. The Fanconi anaemia/BRCA pathway. Nat Rev Cancer. 2003;3(1):23-34.

2. Dror $\mathrm{Y}$, Freedman MH. The Inherited Pancytopenias. In: Kliegman RM, Stanton BF, St Geme JW, Schor NF. (eds.) Nelson textbook of paediatrics. 20th ed. Philadelphia. Elsevier Publishing; 2016. p2362-70.

3. Olson TS. Management and prognosis of Fanconianemia. Available from: https://www.uptodate.com/contents/ management-and-prognosis-of-fanconianemia (Accessed 3rd November 2017).

4. Tischkowitz MD, Hodgson SV. Fanconi anaemia. J Med Genet. 2003;40(1):1-10.

5. Segel BG, Lichtman MA. Aplastic Anemia: Acquired and Inherited. In: Lichtman MA, Kipps TJ, Seligsohn U. William Hematology. 8th ed. China: McGraw-Hill; 2010. p586. 